\title{
Effect of cobalt on nickel oxide toward reduction behaviour in hydrogen and carbon monoxide atmosphere
}

\begin{abstract}
The reduction behaviour of cobalt doped with nickel oxide and undoped nickel oxide $(\mathrm{NiO})$ by hydrogen $(\mathrm{H} 2)$ in nitrogen $(20 \%, \mathrm{v} / \mathrm{v})$ and carbon monoxide $(\mathrm{CO})$ in nitrogen $(40 \%, \mathrm{v} / \mathrm{v})$ atmospheres have been investigated by temperature programmed reduction (TPR). The phases formed of partially and completely reduced samples were characterized by X-ray diffraction spectroscopy (XRD). TPR results indicate that the reduction of Co doped and undoped nickel oxide in both reductants proceed in one step reduction $(\mathrm{NiO} \rightarrow \mathrm{Ni})$ without intermediate. TPR results also suggested that by adding $\mathrm{Co}$ metal into $\mathrm{NiO}$, the reduction to metallic $\mathrm{Ni}$ by both reductant gaseous give different intensity of the peak. The reduction process of Co and undoped $\mathrm{NiO}$ become faster when $\mathrm{H} 2$ was used as a reductant. Furthermore, in $\mathrm{H} 2$ atmosphere, Co-NiO give complete reduction to metallic $\mathrm{Ni}$ at $700{ }^{\circ} \mathrm{C}$. Meanwhile, XRD analysis indicated that $\mathrm{NiO}$ without Co composed better crystallite phases of $\mathrm{NiO}$ with higher intensity.
\end{abstract}

Keyword: Carbon monoxide; Cobalt; Nickel Oxide; Reduction; TPR 